\title{
Produção escrita e desenvolvimento da atividade linguageira"relatar": uma experiência com alunos universitários por meio da plataforma Moodle
}

Eliane Gouvêa Lousada

Raquel de Oliveira Amorim ${ }^{b}$

\section{Resumo}

Este artigo tem por objetivo apresentar um estudo sobre a produção escrita de alunos universitários implicados no aprendizado do francês como língua estrangeira, tendo em vista o lugar privilegiado da escrita como instrumento de desenvolvimento das capacidades de linguagem. Para tanto, a pesquisa baseia-se no quadro teórico-metodológico do interacionismo sociodiscursivo (ISD), conforme os estudos de Bronckart (1999, 2006, 2008), principalmente no tocante à utilização dos gêneros textuais como meio de aceder ao ensino-aprendizagem das linguas (Schneuwly; Dolz, 2004). O estudo consistiu na análise de produções escritas de alunos do segundo semestre da disciplina de Língua Francesa, através do modelo de análise de textos do ISD, contemplando o contexto de produção e a arquitetura textual. Os textos produzidos pelos alunos foram analisados de modo a traçar seu itinerário de aprendizagem e assim identificar como os aprendizes se relacionam com os diferentes papeis sociais que ocupam a cada situação, além de verificar como tais condições refletem na

1 Trata-se de um projeto desenvolvido nas aulas de Língua Francesa 1 e 2, ministradas pela Profa. Dra. Eliane G. Lousada, cujos textos produzidos foram analisados em uma pesquisa de Iniciação Científica pela aluna Raquel de Oliveira Amorim, orientada pela mesma professora. apropriação das capacidades de linguagem (de ação, discursivas e linguístico-discursivas). Os resultados apontam para a pertinência dessa abordagem para o desenvolvimento das capacidades de linguagem $e$, portanto, da aprendizagem da escrita em francês.

Palavras-chave: Produção escrita. Atividade linguageira. Gênero textual.

Recebido em dezembro de 2013 Aprovado em abril de 2014.

a USP - Universidade de São Paulo. Departamento de Letras Modernas. São Paulo, São Paulo, BR. elianelousada@uol.com.br

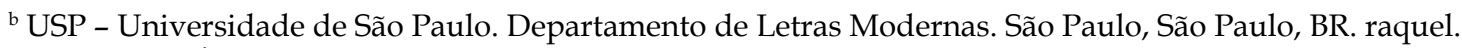
amorim@usp.br 


\section{Introdução}

Neste artigo, visamos a apresentar um estudo sobre a produção de textos escritos, baseados em diversos gêneros textuais, por um grupo de estudantes universitários de Letras-francês, realizados em autonomia e diponibilizados por meio da plataforma Moodle. O objetivo específico da pesquisa é analisar, durante um semestre, o desenvolvimento das capacidades de linguagem dos alunos, sobretudo as capacidades discursivas relacionadas à atividade de linguagem "relatar", através da produção escrita de textos pertencentes a cinco gêneros textuais. O projeto faz parte de uma série de reflexões sobre a produção escrita na Universidade que vem sendo desenvolvidas pelo Laboratório de Letramento Acadêmico ${ }^{2}$ do DLM-FFLCH-USP e, também, representa as pesquisas desenvolvidas pelo Grupo ALTER-AGE-CNPq ${ }^{3}$, com sede na Universidade de São Paulo. Com efeito, o grupo tem desenvolvido, desde a sua fundação, em 2011, pesquisas com três focos principais: o foco aprendizagem de língua pelos alunos; o foco artefatos e instrumentos que propiciam a aprendizagem tanto da língua, quanto do trabalho do professor de língua; o foco trabalho educacional. Os três focos estão interligados e são permeados por uma problemática geral, a do "trabalho de ensinar" (FAÏTA, 2004, 2011).

No caso das pesquisas que envolvem a língua francesa, um dos focos que procuramos desenvolver é o da aprendizagem da língua francesa por alunos de diferentes contextos, baseada na ideia de agir por meio da linguagem, a partir da perspectiva dos gêneros textuais. Assim, pretendemos verifi-

${ }^{2}$ Laboratório de Letramento Acadêmico foi fundado em 2012 pelas Profas. Dras. Marília Ferreira, que atua na área de inglês como língua estrangeira e Eliane G. Lousada, que atua na área de francês como língua estrangeira, além de outros professores da FFLCH-USP.

${ }^{3}$ Grupo ALTER-AGE tem como líder a Profa. Dra. Eliane G. Lousada, como vice-líder a Profa. Dra. Luzia Bueno e promove pesquisas no âmbito da língua estrangeira e da língua materna. car como os alunos aprendem línguas por meio dos gêneros textuais, quer sejam gêneros da esfera cotidiana ou gêneros da esfera acadêmica, buscando verificar como se desenvolvem no que diz respeito à suas capacidades de linguagem e como se tornam (mais) proficientes em relação ao francês.

Um segundo foco de nossas pesquisas é a elaboração de material didático a partir dos gêneros textuais e, portanto, visa a examinar e/ou a propor a elaboração de modelos didáticos, sequências didáticas, projetos, currículos, entre outros. Esse foco está bastante ligado ao anterior, mas busca propor análises e reflexões sobre o material didático em si e sobre seu próprio processo de elaboração, ressaltando o papel que eles podem ter no desenvolvimento dos alunos de francês, ou de outras 
línguas. Como no foco anterior, os estudos sobre material didático para produção escrita acadêmica e universitária também nos parecem de grande importância e estão sendo realizados.

Finalmente, um terceiro foco de nossas pesquisas é o trabalho do professor que atua junto aos aprendizes de língua francesa, aplicando o material didático ou elaborando seu próprio material. Nesse foco, interessa-nos estudar o ensino como um trabalho (MACHADO, 2004; MACHADO, LOUSADA, FERREIRA, 2011), ou seja, o trabalho de ensinar (FAÏTA, 2004; 2011), procurando compreender como o professor exerce sua atividade profissional, como enfrenta as dificuldades inerentes a seu contexto e como encontra soluções para elas. Portanto, fazem parte desse grupo de pesquisas todas as questões relativas à formação dos professores para o trabalho de ensino.

Este artigo inscreve-se, assim, dentro do escopo de pesquisas que acabamos de expor e, mais especificamente, nos focos aprendizagem do aluno e artefatos e instrumentos para o trabalho de ensinar. Dessa forma, apresentaremos uma experiência de produção escrita com alunos do primeiro ano da graduação em francês, procurando mostrar como as atividades baseadas em gêneros textuais, disponibilizadas na plataforma Moodle e focalizando sobretudo a atividade linguageira relatar contribuiram para o desenvolvimento de suas capacidades de linguagem. Para tanto, apontaremos inicialmente o quadro teórico no qual nos baseamos, o Interacionismo Sociodiscursivo (BRONCKART, 1999, 2006, 2008, 2010); descreveremos, em seguida, o contexto em que a pesquisa foi realizada, os participantes e o material didático elaborado para, finalmente, expor nossas análises e as conclusões a que chegamos.

\section{O interacionismo sociodiscursivo}

O Interacionismo Sociodiscursivo (ISD) foi desenvolvido por pesquisadores da Universidade de Genebra, sobretudo Bronckart (1999, 2006, 2008, 2010), a partir da década de 80, a partir de pesquisas empíricas que tinham como um dos objetivos principais repensar o ensino da produção escrita nas escolas. Segundo o autor, o ISD é uma corrente do Interacionismo Social baseado, em primeira instância, nos estudos de Vigotski (1997) sobre o desenvolvimento na ontogênese e sobre o papel dos instrumentos psicológicos no desenvolvimento 
humano. Devido a esse objetivo maior, a obra de Vigotski (1997) enfatiza o papel da aprendizagem escolar como fator que contribui para o desenvolvimento das pessoas e, portanto, é um dos autores mais importantes para o ISD. Além desse autor, Bronckart $(1999,2006,2008,2010)$ aponta inúmeros outros teóricos que tiveram influência na constituição do ISD, dentro os quaismerece destaque, neste artigo, Valentin Voloshinov (1977), cuja preocupação era o estudo das relações entre as atividades humanas e os textos, sustentando que as pesquisas devem partir das interações sociais em seu contexto, em seguida analisar os gêneros produzidos nessas interações e, finalmente, interessar-se pelas unidades e estruturas linguísticas no interior dos gêneros.

A partir dessas bases teóricas e tendo como um dos objetivos repensar o ensino da produção escrita nas escolas suíças, Bronckart (2010) propõe um modelo de análise textual que se organiza a partir de quatro níveis:

a) nível da ação de linguagem, ou seja, o fato de que, em uma dada situação, uma pessoa produz um texto com um determinado objetivo;

b) nível do texto, considerado como uma unidade comunicativa e sendo o correspondente empírico de uma ação de linguagem. Nesse nível, leva-se em conta o fato de que o texto pertence a um gênero, pois é construído a partir de modelos disponíveis no arquitexto e adaptado a uma determinada ação de linguagem;

c) nível dos tipos de discurso, que é um conceito particular do ISD, pois propõe a compreensão da produção textual do ponto de vista das escolhas feitas pelo enunciador ao criar mundos discursivos que se organizam a partir de dois tipos de operações de linguagem: a primeira diz respeito à conjunção-disjunção, ou seja àpresença de um conteúdo temático colocado à distância (disjunto - NARRAR) do produtor do texto ou não (conjunto - EXPOR); a segunda operação de linguagem diz respeito à implicação-autonomia e exprime a relação do produtor do texto com a situação de ação de linguagem, que pode deixar marcas no texto (implicação) ou não (autonomia). Do cruzamento dessas operações de linguagem (conjunção-disjunção e implicação-autonomia), surge o que Bronckart $(1999,2010)$ chama de tipos de discurso, que correspondem a quatro diferentes mundos discursivos: no eixo do NARRAR, 
temos o mundo discursivo do narrar autônomo que dá origem ao tipo de discurso narração e o narrar implicado que dá origem ao relato interativo; no eixo do EXPOR, temos o mundo discursivo do expor autônomo que dá origem ao discurso teórico e o mundo discursivo do expor implicado que dá origem ao discurso interativo.

d) nível dos mecanismos de textualização, que podem ser definidos como uma série de procedimentos linguísticos que visam a assegurar a coerência temática (correspondente à conexão e à coesão nominal) e a coerência enunciativa (correspondente à distribuição das vozes e das modalizações) de um texto.

Esse modelo de análise textual deu origem a uma série de pesquisas e trabalhos empíricos, em recepção e em produção, que partem da observação de textos para propor sequênciasdidáticas e, em seguida, sugerema análise das produções dos alunos ao desenvolverem essas atividades. As pesquisas e trabalhos realizados a partir dele foram conduzidas tanto emGenebra (SCHNEUWLY; DOLZ, 2004), quanto em Portugal (COUTINHO, 2012), na Argentina (RIESTRA, 2010) e no Brasil (GUIMARÃES, MACHADO, COUTINHO, 2007; MACHADO, LOUSADA, 2010; MACHADO; ABREU-TARDELLLI;CRISTOVÃO,2009); tanto em língua materna, seja o francês (DOLZ; GAGNON TOULOU, 2008)ou o português (MACHADO, ABREU-TARDELLI, LOUSADA, 2004a, 2004b, 2005, 2007; BUENO, 2011; LOUSADA, MUNIZ-OLIVEIRA, BARRICELLI, 2011; GUIMARÃES; KERSCH, 2012), quanto em língua estrangeira (CRISTOVÃO, 2002, 2008, 2009; LOUSADA, 2009, 2010, 2012; ROCHA; LOUSADA, 2012; GUIMARÃES-SANTOS, 2012). Muitas das pesquisas em língua estrangeira tem sido desenvolvidas em torno da língua inglesa e, por isso, este artigo se propõe a contribuir para as pesquisas em francês, que estão sendo conduzidas atualmente por membros do grupo ALTER-AGE.

\section{A produção escrita e os gêneros textuais pelo prisma do ISD}

Como dissemos, a noção de gênero de texto tem sido amplamente adotada no campo da didática das línguas e muitas pesquisas apoiam-se nos trabalhos desenvolvidos por 
Schneuwly e Dolz (2004), na continuidade dos estudos de Bronckart $(1985,1999)$. Para esses autores, o objetivo do ensino de gêneros textuais não deve ser limitado à aprendizagem do gênero em si: ao contrário, ele deve centrar-se, sobretudo, no desenvolvimento das capacidades de linguagem que poderão ser utilizadas na produção de outros gêneros textuais. Para desenvolver essa ideia, Schneuwly e Dolz (2004) apoiam-se na noção de instrumento, desenvolvida por Vigotski (1997) e, em primeira instância, marxista, segundo a qual, no trabalho, o homem opera uma modificação desejada no objeto, com o uso de ferramentas, consideradas meios de trabalho. Essas ferramentas estariam entre o homem e a situação na qual ele age, guiando seu comportamento nessa situação, mediando a relação entre o homem e o objeto, mas também entre o homem e os outros. Porém, Vigotski (1997) dá destaque especial ao papel dos instrumentos que ele chama de psicológicos, de natureza primeiramente social, mas que foram apropriados ao longo da ontogênese, passando de interpessoais a intrapessoais. Os instrumentos psicológicos, diferentemente das ferramentas, visam à transformação do próprio comportamento do indivíduo. Segundo Shcneuwly e Dolz (2004), nesse processo, não apenas a natureza é transformada, mas também o próprio instrumento e, em última instância, o próprio comportamento humano. Friedrich (2012) explicita a diferença apresentada por Vigotski (1997) entre a ferramenta de trabalho e o instrumento, explicando que ambos são elementos intermediários, intercalados entre a atividade do homem e seu objeto.Porém, a ferramenta de trabalho serve para operar mudanças no mundo dos objetos, como por exemplo, um martelo, que serve para colocar pregos na parede. Por outro lado, os instrumentos psicológicos não visam a fazer mudanças no mundo exterior, mas na atividade psíquica do sujeito, sendo, portanto, um modo de influência do sujeito sobre si mesmo, um meio de autorregulação e de autocontrole. Dessa forma, o instrumento psicológico mediatizaria e materializaria a atividade, podendo ser considerado como um local privilegiado da transformação de comportamentos. Sendo assim, para Schneuwly e Dolz (2004), os gêneros poderiam também servir de instrumentos psicológicos (ou "mega-ferramentas", como dizem os autores), no sentido de que contribuiriam para o desenvolvimento das 
capacidades linguageiras. Aí reside uma das grandes motivações para o ensino dos gêneros textuais, que ultrapassa o ensino-aprendizagem de um gênero em específico. Trata-se, nesta perspectiva, de considerar o ensino dos gêneros textuais em uma perspectiva vigotskiana do desenvolvimento, como sugerem Machado e Lousada (2010).

Portanto, ao considerar que os gêneros são um instrumento psicológico para o desenvolvimento das capacidades de linguagem (SCHNEUWLY; DOLZ, 2004), assumimos que o trabalho com gêneros textuais não age apenas na aprendizagem de um gênero, pois ele permite que os alunos se apropriem ou desenvolvam as capacidades de ação, as capacidades discursivas e as capacidades linguístico-discursivas. As capacidades de ação referem-se à mobilização de representações sobre a situação de comunicação e sobre seu referente. As capacidades discursivas remetem à organização geral do texto, envolvendo a escolha pela disposição dos conteúdos temáticos, pelos tipos de discurso e pelas eventuais sequências. Já as capacidades linguístico-discursivas referem-se à seleção de unidades linguísticas necessárias para assegurar a coerência temática e a coerência pragmática dos textos. É preciso ressaltar, no entanto, que as três capacidades de linguagem são interdependentes e que o desenvolvimento de uma delas muitas vezes implica na progressão das outras.

A partir dessa visão dos gêneros como instrumentos que contribuem para o desenvolvimento de capacidades de linguagem que podem ser transpostas para outras situações de produção textual, podemos inferir, por exemplo, que quando aprendemos a redigir um artigo de opinião, desenvolvemos também: a capacidade para identificar a situação de produção que é polêmica e demanda uma posição argumentativa; a capacidade para argumentar e organizar o texto de forma argumentativa; a capacidade para utilizar os conectivos pertinentes em uma outra situação percebida como polêmica e, portanto, que demanda persuasão. Nesse sentido, os gêneros seriam considerados como instrumentos psicológicos que poderiam ser utilizados pelos alunos para desenvolver suas capacidades de linguagem para que possam usá-las em outras situações de uso da língua, para a produção de outros gêneros textuais.

Para Dolz, Gagnon e Toulou (2008, p. 12), a análise das capacidades de linguagem dos alunos e a identificação das difi- 
culdades de produção escrita são necessárias para a adaptação do ensino às necessidades reais do contexto:

L'analyse des capacités langagières des apprenants et l'identification de leurs problèmes d'écriture sont donc des conditions pour adapter l'enseignement à leurs besoins. A celles-ci s'ajoute l'analyse des dimensions de l'écriture et des composantes du texte à produire.

Optamos, neste artigo, por centrar nossas discussões no desenvolvimento das capacidades discursivas dos alunos, sobretudo no que diz respeito à operação linguageira "relatar", pois ela se revelou a mais apropriada para nosso contexto, como veremos a seguir.

\section{Contexto da pesquisa e procedimentos metodológicos}

A presente pesquisa foi desenvolvida com alunos do segundo semestre do curso de Língua Francesa da habilitação em francês da Universidade de São Paulo. Os estudantes que chegam a esse estágio estão geralmente cursando o segundo ano do curso de Letras, mas o primeiro ano de francês, e a maioria também segue concomitantemente a habilitação em português. O currículo seguido no primeiro ano é organizado em torno de funções comunicativas e de aspectos linguísticos que permitem a sua realização.

Desde 2009, temos desenvolvido uma aproximação dos conteúdos existentes no currículo, que havia sido elaborado em 2008, com a perspectiva dos gêneros textuais. Em outras palavras, temos procurado desenvolver atividades para a compreensão e produção de gêneros textuais que permitem a realização das funções comunicativas presentes no currículo. Nessa perspectiva, propusemos um currículo paralelo, organizado em torno das atividades de produção escrita, em função de gêneros textuais que seriam produzidos pelos alunos ao aprenderem determinadas funções comunicativas. No caso da disciplina Francês 2, uma das funções comunicativas mais importantes constantes do currículo era "contar acontecimentos passados", o que nos levou a escolher a atividade de linguagem "relatar" para nossas produções escritas. Portanto, no segundo semestre da habilitação em Francês, em 2012, os alunos desenvolveram os seguintes gêneros textuais: sinopse 
de filme, notícia insólita publicada em jornal, relato de viagem em um blog, email informal, relato literário curto, com o objetivo de desenvolver as capacidades de linguagem explicitadas no quadro abaixo:

\begin{tabular}{|c|c|c|c|}
\hline Gêneros textuais & Capacidades de ação & $\begin{array}{l}\text { Capacidades } \\
\text { discursivas }\end{array}$ & $\begin{array}{l}\text { Capacidades linguístico- } \\
\text { discursivas }\end{array}$ \\
\hline Sinopse de filme & $\begin{array}{l}\text { O enunciador apresenta } \\
\text { os personagens e relata } \\
\text { fatos mais importantes } \\
\text { de um filme a possíveis } \\
\text { espectadores, sem } \\
\text { revelar o final }\end{array}$ & Relatar & $\begin{array}{l}\text { Predominância de verbos no } \\
\text { présent, futur proche e passé } \\
\text { composé } \\
\text { Presença de adjetivos e pronomes } \\
\text { assegurando a coesão nominal e } \\
\text { permitindo descrever em pouco } \\
\text { espaço. }\end{array}$ \\
\hline $\begin{array}{l}\text { Notícia "insólita" } \\
\text { publicada em jornal }\end{array}$ & $\begin{array}{l}\text { O enunciador relata um } \\
\text { fato insólito ocorrido a } \\
\text { leitores de um jornal, } \\
\text { procurando chamar a } \\
\text { atenção do leitor }\end{array}$ & Relatar & $\begin{array}{l}\text { Predominância de verbos no } \\
\text { présent, passé composé, imparfait; } \\
\text { presença de organizadores } \\
\text { temporais } \\
\text { Mecanismos de coesão nominal } \\
\text { por meio de retomadas que } \\
\text { demonstram certo posicionamento } \\
\text { enunciativo do produtor do texto } \\
\text { Inserção de vozes }\end{array}$ \\
\hline $\begin{array}{l}\text { Relato de viagem } \\
\quad \text { em um blog }\end{array}$ & $\begin{array}{l}\text { O enunciador relata (a } \\
\text { amigos ou não) fatos } \\
\text { ocorridos durante } \\
\text { a viagem e expõe as } \\
\text { características do local } \\
\text { visitado }\end{array}$ & Relatar & $\begin{array}{l}\text { Predominância de verbos no } \\
\text { présent, imparfait, passé composé } \\
\text { e futur proche; presença de } \\
\text { organizadores temporais } \\
\text { Presença de substantivos e } \\
\text { adjetivos que caracterizam o lugar } \\
\text { visitado } \\
\text { Inserção de vozes (voz do lugar) }\end{array}$ \\
\hline Email informal & $\begin{array}{l}\text { O enunciador relata a } \\
\text { um amigo o que tem } \\
\text { feito nos últimos } 6 \\
\text { meses, pede informações } \\
\text { sobre obtenção de bolsa } \\
\text { etc. }\end{array}$ & Relatar & $\begin{array}{c}\text { Predominância de verbos no } \\
\text { présent, passé composé e futur } \\
\text { proche }\end{array}$ \\
\hline $\begin{array}{l}\text { Relato literário } \\
\text { curto (a partir do } \\
\text { estudo de alguns } \\
\text { textos do livro de } \\
\text { Ph. Delerm) }\end{array}$ & $\begin{array}{l}\text { O enunciador produz } \\
\text { um pequeno texto } \\
\text { literário, sobre um } \\
\text { objeto ou uma ação do } \\
\text { cotidiano }\end{array}$ & Relatar & $\begin{array}{l}\text { Predominância de verbos no } \\
\text { présent e passé composé }\end{array}$ \\
\hline
\end{tabular}

Tabela 1 : Gêneros trabalhados com os alunos e capacidades de linguagem dominantes 
Durante as aulas, foram desenvolvidas atividades didáticas para trabalhar os gêneros indicados acima, tendo sido exploradas suas principais características. Considerando o fato de que os alunos dispunham de apenas duas aulas semanais para a aprendizagem, as atividades de produção escrita foram realizadas fora da sala de aula e foram entregues pela plataforma Moodle. Cabe ressaltar que as atividades disponibilizadas na plataforma continham, além da proposta de produção escrita, perguntas e exercícios que visavam à observação de mais um exemplar do gênero, antes de solicitar a produção textual. Nesse sentido, salientamos o importante papel da plataforma no curso, já que ela funciona como um verdadeiro auxiliar para a aprendizagem dos alunos, pois possibilita a disposição das atividades e de links para outros exemplares do gênero, a entrega dos textos produzidos e dos comentários sobre eles, com as devidas correções, entre outros. Além disso, parece-nos importante mencionar o papel da plataforma para a coleta de dados de pesquisa, já que o arquivamento permite o acesso a todas as produções com a data de entrega e os comentários feitos pelo professor, tornando-se, assim, um interessante auxiliar para a coleta de corpora para pesquisas sobre produção textual.

Quanto à coleta do corpus, foi necessário delimitar o número de alunos, já que as duas classes, diurna e noturna, no segundo semestre de 2012 totalizariam cerca de 50 alunos, o que inviabilizaria um estudo mais aprofundado de seus textos escritos. Na verdade, a presente pesquisa configura-se como continuação dos estudos iniciados por Bezerra (2012) ${ }^{4}$, com praticamente os mesmos alunos. Porém a pesquisa de Bezerra (2012) concentrou-se nas produções do primeiro semestre (Francês 1), enquanto que a pesquisa aqui apresentada focaliza os textos dos alunos do segundo semestre(Francês 2) da habilitação. Cada um dos cursos em que foram coletadas produções escritas contava com cerca de 50 alunos, se somados os períodos matutino e noturno. Conforme apontado por Bezerra (2012), embora a observação de todas as produções escritas tenha trazido dados importantes ao estudo, a grande

4 Trata-se, também, de uma pesquisa de Iniciação Científica, realizada no mesmo contexto e com a mesma orientação, mas focalizando todas as produções textuais da classe. quantidade de aprendizes dificultou o trabalho de análise. Assim, sentimos a necessidade de restringir a cerca de sete os estudantes cujas produções fariam parte de nossas análises. Para a escolha dos alunos, optou-se, à semelhança do que fez Petreche (2008), escolher alguns alunos de bom desempenho, 
alguns com desempenho um pouco inferior e ainda outros que apresentassem diversas dificuldades em seus processos de aprendizagem. Dessa forma, pudemos desenvolver alguns critérios para a delimitação do corpus, como descrevemos abaixo:

- ter produzido no mínimo três dos cinco textos pedidos. Como o objetivo era acompanhar o desenvolvimento dos alunos de uma produção à outra, não poderíamos trabalhar com apenas uma ou duas produções escritas. Assim, diversos aprendizes tiveram que ser descartados, por terem efetuado poucas produções escritas.

- não ter um nível de francês visivelmente mais elevado do que os outros alunos da turma;

- manter uma boa distribuição entre os alunos da classe, garantindo alguns com bom desempenho, outros com desempenho médio e outros com maiores dificuldades, para manter a representatividade do estudo.

Para colocar em prática os critérios acima, baseamo-nos nas observações da professora sobre a classe que tinha iniciado seus estudos no primeiro semestre de 2012 e que praticamente não havia mudado no período de coleta dos dados, entre agosto e dezembro de 2012. A tabela a seguir mostra o desempenho dos alunos no início da pesquisa, a quantidade de produções escritas (PE) feitas por cada um e a que período (matutino ou noturno) pertencem.

\begin{tabular}{|c|c|c|c|}
\hline Aluno & Desempenho & PE entregues & Períodode estudo \\
\hline R.F. & Muitadificuldade & 5 & Noturno \\
\hline C.S. & Poucadificuldade & 4 & Noturno \\
\hline V.C. & Poucadificuldade & 4 & Noturno \\
\hline R.G. & Poucadificuldade & 5 & Noturno \\
\hline A.S. & Algumasdificuldades & 5 & Matutino \\
\hline G.S. & Algumasdificuldades & 5 & Matutino \\
\hline S.C. & Muita dificuldade & 3 & Matutino \\
\hline
\end{tabular}

Tabela 2: características dos alunos escolhidos

Com essa tabela, vemos que foram sete os alunos selecionados, depois de observados todos os critérios que descrevemos. Vejamos, então, como analisamos os dados coletados. 


\section{Discussão dos resultados}

Nesta seção, mostraremos uma breve descrição de cada gênero trabalhado com os alunos, seguida de comentários sobre seu desempenho ao produzi-los. Finalmente, apresentaremos tabelas com o objetivo de comparar o desenvolvimento dos alunos nas diferentes atividades de produção escrita e em relação às capacidades de linguagem.

A primeira atividade proposta referia-se à produção de uma sinopse de filme, indicado nas instruções do exercício ou escolhido livremente pelos alunos. $\mathrm{O}$ gênero em questão tem como suportes mais comuns a contra capa de DVDs e Blu-Ray e sites especializados em filmes. Em classe, as sinopses trabalhadas vinham do site allocine.fr, que é bastante popular na comunidade francófona e que contém vasta gama de sinopses disponíveis ao público. O intuito do texto, quando extraído de uma contracapa é de seduzir o leitor a assistir o filme, pois assim sua venda será efetuada. No caso de um site como allocine. fr, o objetivo é manter o status do site como fornecedor de boas sinopses e contentor de bom conteúdo. A inserção de elementos que caracterizem o filme como interessante e a manutenção do suspense são indispensáveis na produção do gênero, pois o texto não pode revelar o final do filme.

O tipo de discurso que constitui a sinopse é o relato interativo. Segundo Bronckart (2010), o relato interativo pode conter sequências descritivas e as narrativas. Retomando outros autores, o autor sugere cinco fases constituintes dessa sequência: situação inicial, complicação, ações, resolução e situação final. A essas podem juntar-se outras duas : avaliação e moral. Na sinopse, dado que é impossível revelar o final da trama, a sequência narrativa se limitará às duas primeiras fases, finalizando, portanto, num nó que constitui a intriga e que motiva o leitor a assistir ao filme, a fim de descobrir quais ações serão empreendidas para a resolução do problema. É possível, no entanto, identificar neste gênero algumas etapas comuns que constituem as duas primeiras fases:

- apresentação: nomeação e caracterização do(s) protagonista(s) e, frequentemente, instituição da origem espaço-temporal;

- evento: acontecimento de relativa importância que transforma a situação inicial e que possibilita a complicação; 
- construção da complicação: etapa em que elementos diversos (ações, características das personagens ou da situação) constroem as condições necessárias à complicação;

- projeção pós-complicação: uso de formas de futuro próximo. Monta hipóteses acerca das ações decorrentes da complicação e sua resolução. É um último esforço para instigar a curiosidade do leitor.

Também é comum introduzir previsões acerca dos benefícios morais que o protagonista descobrirá em sua jornada, configurando-se, portanto, em outra modalidade da etapa final, que simula a própria fase da moral. Sua ocorrência na sinopse se justifica como uma maneira de convencer o leitor de que, assistindo ao filme, ele também terá acesso às lições de vida aprendidas pelas personagens.

Quanto à coesão verbal, o gênero sinopse se desenvolve principalmente através do indicatif présent, que Bronckart (1999) chama de présent de narration, quando usado para apresentar progressão de ações no passado. Além disso, o uso de pronomes na terceira pessoa com função anafórica é comum, a fim de evitar repetições. Por último, é necessário apontar a importância das modalizações para aumentar o suspense e o efeito de sedução, normalmente colocando o leitor a favor do protagonista e ajudando-o a enxergar de maneira intensificada a complicação da narrativa. Tendo tais características em vista, verificaremos as produções dos alunos, procurando identificar suas capacidades de linguagem.

No que diz respeito às capacidades de ação, todos os alunos compreenderam que, na atividade social proposta, era necessário cumprir a função de enunciador que instiga o destinatário a assistir o filme. No entanto, observamos em alguns textos a inserção da opinião do autor, à semelhança do gênero resenha. $\mathrm{O}$ exemplo a seguir encontra-se próximo ao final da produção de C.S: "C'est un filme très marrante, et on ne sais jamais quoi espérer." A inadequação da frase reside no fato de que no gênero sinopse raramente faz-se adjetivações diretamente ligadas ao filme, usando-se, de preferência, modalizações apreciativas referentes ao elementos constitutivos da história, como personagens, lugares, situações. Assim, no exemplo dado era esperado que o aluno, ao invés de afirmar que o filme é engraçado, expusesse ao leitor tal característica inserindo adjetivações quanto aos personagens, por exemplo, 
de maneira que deixasse implícito sua comicidade. A supressão das adjetivações a favor de uma subjetivação genérica não se encaixa, portanto, nas expectativas quanto ao gênero. Esse ponto é importante porque é uma das características que diferencia a resenha da sinopse. Enquanto no primeiro espera-se encontrar a opinião do autor sobre o filme, no segundo procura-se somente um pequeno resumo e a caracterização da história.

No que diz respeito às capacidades discursivas, como já dissemos, nas sinopses não se deve avançar além da fase de complicação, para que o leitor queira assistir ao filme. Todos os estudantes identificaram satisfatoriamente essa fase, construindo os textos de forma a conduzir à complicação da narrativa. A única exceção foi R.F., que não propôs uma situação de conflito, nem construiu um momento de tensão. Porém, na classe como um todo, a construção do suspense ficou prejudicada em decorrência de dois aspectos presentes nas produções dos alunos: supressão de dados importantes através de subjetivações e revelação abrupta da complicação, sem instaurar intensificação suficiente. Por exemplo, em alguns casos, o aluno omite ações que poderiam intensificar o suspense com subjetivações genéricas, como nas frases "Mais la guerre n'est pas finis et ils ont affronter divers problèmes et obstacles, jusqu'à qu'ils finalement retrouvent Ryan" (G.S.)e "Ellis devient un vrai ami et l'aide à affronter nombreuses situations dificilles." (R.G.) A inadequação das frases sublinhadas reside no fato de que são aplicáveis a quase qualquer filme no intento de valorizá-lo, o que não permite que os filmes sobre os quais se escreve sejam reconhecidos como mais desejáveis que outros. O mesmo ocorre na produção de R.F: « Dans le voyage le garçon connaît beaucoup de personnes differents. Cette personne enseignent Alexander beaucoup choses sur la vie et il enseigne beaucoup choses pour cette personnes aussi. " No exemplo, o aluno também não intensifica nem caracteriza satisfatoriamente as experiências do protagonista, fazendo com que o trecho, que deveria ser a etapa de projeções pós-complicação, não cumpra sua função de apresentar ao leitor conhecimentos ou sensações que poderão ser acessados unicamente assistindo ao filme.

Ao invés de tais supressões, seria mais adequado ao gênero inserir dados exclusivos do filme sobre o qual se escreve. Sobre um filme de guerra, por exemplo, ao invés de afirmar que os personagens enfrentarão diversos problemas e obstáculos, é pre- 
${ }^{5}$ Durante as aulas, os alunos foram apresentados ao gênero sinopse de filme através de dois textos do site allocine.fr. Um deles foi a sinopse do longa Le Petit Nicolas (2010). $\mathrm{O}$ trecho que trazemos como exemplo logo a seguir, diz respeito ao filme Ratatouille, cuja sinopse encontra-se disponível em http://www.allocine. fr/film/fichefilm_gen_ cfilm $=46211$.html (acessado em jan/2013). ferível nomear as dificuldades, como fome, exaustão, saudade etc., seguindo o que se encaixa melhor à história. No modelo apresentado aos alunos ${ }^{5}$, é possível observar a nominalização de elementos ao invés de suprimi-los de maneira genérica: "Ecartelé entre son rêve et sa condition, Rémy va découvrir le vrai sens de l'aventure, de l'amitié, de la famille..." Aqui, o autor, no intento de seduzir o leitor, prefere expor-lhe os valores específicos a que terá acesso assistindo ao filme ao invés de dizer vagamente que Rémy vai descobrir muitas coisas sobre a vida.

Quanto à revelação abrupta da complicação, podemos defini-la como uma falha na etapa de projeção, como nos exemplos a seguir, que dizem respeito à última linha de duas produções, quando a complicação de cada uma é instaurada, sem nenhuma outra manifestação que seduza o leitor: "Maria prend l'affection et le respect des enfants mais elle se tombe amoureuse du capitaine." (V.C.) e "Mais bientôt, des leçons de piano deviennent les rencontres sexuelles et aucun retard pour les deux tombent amoureux » (A.S.). As supressões e a revelação abrupta da complicação podem ser compreendidas como certa dificuldade na representação do destinatário e de suas expectativas quanto ao gênero. $\mathrm{O}$ segundo desses dois aspectos também pode ser entendido como uma dificuldade nas capacidades discursivas, ou seja, um problema na organização do texto.

Quanto às capacidades linguístico-discursivas, é possível observar a instituição da origem espaço-temporal. Cinco alunos conseguiram instituí-la. R.F., no entanto, apesar de estabelecer uma ação que marca o tempo ("Il termine les etudies sur medicine"), não consegue utilizar uma palavra ou expressão como quand ou le jour où que indique que aquela é uma ação marco para o desenrolar da história: "Alexander est un garçon dans une famille americaine tradicionalle. Il termine les etudies sur medicine et gagne une voiture ses parents, mais Il ne se sent pas complet et heureux. Ensuite Alexander decide quiter son maison... ", assim, o ensuite acaba não fazendo referência clara a nenhum momento específico. Já o aluno G.S. indicou uma origem espaço-temporal suficiente para o sistema de conexão, mas insatisfatória para a compreensão do filme, já que não aponta qual a guerra ou período em que se passa a história: "Quand le capitaine John $H$. Miller débarque à Normandie au milieu d'une bataille..." Ainda assim, todos os alunos conseguiram organizar temporalmente 
o corpo do texto, incluindo R.F., que utiliza ensuite para apontar a progressão de ações.

Quanto aos mecanismos de coesão nominal, os alunos mobilizaram bem tanto as anáforas nominais quanto as pronominais. As modalizações apreciativas foram poucas vezes combinadas de forma a caracterizar os personagens, como no caso da aluna A.S., quando se refere à protagonista de sua sinopse como "jeune femme écossaise". Quanto ao aluno R.F., apesar de tentar construir certa coesão, acaba por repetir muitos elementos, como o nome do protagonista.

Passando à segunda atividade proposta, os alunos deveriam produzir um fait divers. Também situado no eixo relatar (Bronckart, 1999), o gênero tem como suporte os jornais cotidianos, o que o torna também disponível nas versões online da imprensa escrita. Lousada (2012) faz a caracterização do gênero e aponta sua semelhança com a notícia, exceto pelo fato de não ter importância social, cultural, política e econômica e por frequentemente abordar eventos curiosos, inusitados ou acidentes, fazendo uso do humor e da ironia. O público-alvo do gênero, portanto, não procura em sua leitura manter-se informado, mas recorre ao fait divers por prazer, como fonte de entretenimento.

Quanto à infraestrutura geral do texto, o gênero, semelhante à notícia, procura responder às questões "O que? Quem? Por quê? Quando? Onde? Como?". Sendo um texto curto e objetivando chocar o leitor, o fait divers usa a estrutura da pirâmide invertida, ou seja, revela primeiramente as informações mais gerais, passando, posteriormente, às mais específicas (FRANCESCHINI, 2004). Assim, logo no título é comum responder a muitas das perguntas-base, deixando somente o como e por quê para serem esclarecidos ao longo do texto. Após o título encontra-se normalmente um subtítulo, seguido por um lead, parágrafo introdutório que termina de responder a todas as questões colocadas acima. O corpo da notícia traz os detalhes que não são fundamentais para a compreensão do fato exposto.

O fait divers se organiza em relato interativo e pertence à atividade de linguagem relatar. A coesão verbal se dá, no caso do francês, principalmente pelos tempos présent de l'indicatif, passé composé e imparfait. No que tange ao sistema de conexão, há o estabelecimento de uma origem espaço-temporal e são usados organizadores temporais ao longo de todo o texto, 
conforme se relata a progressão das ações. Quanto à inserção de vozes, dado que o gênero guarda muitas semelhanças com a notícia, é esperado que seja construído a partir de informações fornecidas por diversos indivíduos e instituições, configurando, assim, um gênero marcadamente polifônico. A escolha dos verbos dicendi utilizados revela uma das marcas do fait divers, uma vez que o autor pode variar a maneira pela aual insere as diferentes vozes, usando uma gama de verbos que vai de dire expliquer a verbos com sentido menos neutro, como interroger e nier.

Por último, é necessário apontar a importância das escolhas lexicais na coesão nominal do gênero. Adjetivando e escolhendo substantivos para os elementos a que o autor remete, $o$ enunciador acaba marcando sua opinião sobre os protagonistas do texto. Lousada (2012) ressalta, a partir de um exemplo de fait divers, o uso de peu rompue aux subtilités de la langue française e son français hésitant, demonstrando o posicionamento do autor quanto às capacidades, em língua francesa, doreferente mencionado no texto. É principalmente pela coesão nominal e pelos índices de subjetividade nela inserida que se dá a ironia comum nos textos de faits divers.

A partir dessas características, podemos analisar primeiramente as capacidades de ação desenvolvidas pelos alunos. Era necessário que tivessem em vista o objetivo do gênero: chocar através de um fato insólito, guardando, entretanto, características em comum com notícias de jornal. Assim, era esperado que os estudantes mobilizassem o formato do gênero para ressaltar o seu caráter inusitado, respondendo às perguntas de base que já apresentamos.

Os alunos S.C. e R.F. não situaram seu leitor utilizando um título. Aqui, o fato importante não é apenas a não utilização do título, mas a não apreensão de uma estratégia importante do gênero: se o fait divers deve ser rápido e chamar a atenção por seu conteúdo insólito, é necessário chocar o leitor desde o primeiro contato com o texto. A leitura do fait divers inteiro só deve ocorrer para uma explicação mais detalhada do que aconteceu, onde, quando e por quê. Ao não colocar o título, não temos uma importante característica do gênero, o que constitui um problema no domínio das capacidades de ação e das capacidades discursivas. É necessário observar, no entanto, 
que ambos os alunos procuraram expressar tal instantaneidade através da primeira frase, que logo fornece os dados necessários para causar a sensação de surpresa.

Os outros alunos responderam bem às perguntas características do gênero, cumprindo o objetivo de chocar o leitor. A.S. e G.S., entretanto, não inseriram as informações sobre local e data nem no título, nem no cabeçalho. Todos os estudantes compreenderam que era necessário construir um discurso disjunto e sem a utilização da primeira pessoa. A inserção de vozes também não foi um problema para a maioria dos aprendizes. Com exceção de R.F., todos inseriram comentários externos através de discurso indireto. R.F. construiu um texto satisfatório, embora não tenha utilizado declaradamente vozes de personagens.

Todos os alunos utilizam bem os tempos necessários ao gênero, inclusive R.F. A única exceção éS.C. que teve problemas na conjugação de verbos pronominais no passé composé ("une femme s'a tué") e não empregou o imparfait, exceto por uma frase em que seu uso não se fazia necessário, sendo preferível o passé composé ("L'APF recevait d'autres affirmations pareilles.").

Por último, no que se refere à coesão nominal, observamos que R.F. usa somente la jeune fille, recorrendo no resto do texto a pronomes ou substantivos sem adjetivação. É perceptível, no entanto, melhora em seu sistema de coesão nominal, ao longo de várias produções escritas. Embora ele não faça mais repetições excessivas, apresenta ainda certa dificuldade com pronomes possessivos. Já a aluna A.S., intensificando ainda mais o que já demonstrava na produção escrita anterior, insere as expressões le propriétaire du magazine, magnat, l'aîné e la vieille femme, focando, através de escolhas lexicais, no dado insólito de seu fait divers, isto é, na idade avançada da protagonista e na posição social do outro personagem. ${ }^{6}$ S.C. à semelhança do que fez R.F., somente utilizou l'ecrivain para retomar femme. Quanto aos outros alunos, nenhum utilizou o mecanismo comum ao gênero, de adjetivação através de retomadas. V.C. e R.G., no entanto, constroem bons faits divers, sem prejuízos à compreensão ou mesmo à adequação ao gênero. G.S., entretanto, fez muitas repetições, tendo empregado poucas retomadas pronominais e nenhuma retomada nominal.

Passando à terceira produção, era proposto que os alunos 
ser publicado em um blog. A atividade social relatar viagens já era encontrada em livros quando passou a ocupar o espaço em blogs. O intuito, então, mais que expor experiências próprias, passou a ser de partilhá-las com leitores que possivelmente rumariam para o mesmo destino, guiando-os, assim, nas dificuldades que poderiam encontrar ou dando dicas de atividades interessantes na região escolhida. Além disso, os relatos de viagem em blogs cumprem o papel de contar aos amigos e familiares, coletivamente, como está ocorrendo a viagem, eliminando, assim, a necessidade de escrita de vários cartões postais ou emails. Exemplo disso é o site francófono e-voyageur.com, que reúne grande quantidade de testemunhos de turistas em diversas regiões do mundo. Tendo em vista as expectativas criadas quanto ao gênero, era necessário que os alunos construíssem um relato interativo, portanto implicado, o que se traduziu no uso intenso da primeira pessoa. Era esperado que os estudantes partilhassem suas perspectivas sobre as situações vividas, fazendo uso de modalizações apreciativas para expressar suas opiniões. É preciso também lembrar que as experiências deveriam ser significativas para uma possível viagem que o leitor pretendesse empreender.

No que tange à infraestrutura geral do gênero, há sempre um título ou cabeçalho que contêm a data, já que os relatos costumam ser divididos em pequenos períodos de tempo, ou seja, a cada poucos dias de viagem faz-se novo texto para partilhar novas experiências. Quando o passeio inclui a visita a diversas regiões também é comum a especificação da localidade que será abordada. O corpo do texto se constitui de maneira bastante livre, apresentando sequências descritivas e principalmente narrativas. Quanto à coesão verbal, o tempo de uso mais comum é o présent de narration, ou seja, o presente usado para contar eventos passados. No entanto, são também usuais relatos que utilizam o passé composé e o imparfait. Tratando-se, portanto, da progressão de ações no eixo da disjunção, era necessário que os alunos estabelecessem uma origem espaço-temporal e que, a partir dela, usassem organizadores temporais para estruturar seus textos.

No que diz respeito ao desenvolvimento das capacidades de ação e discursivas dos alunos, é preciso fazer algumas ressalvas. Normalmente os relatos são feitos com grande riqueza de detalhes, o que implica ou uma grande capacidade de me- 
morização para que o autor consiga lembrar das experiências vividas, ou é necessário que anotações sobre a viagem sejam feitas pouco tempo depois de sua ocorrência. Como é improvável que qualquer um dos alunos dispusesse de qualquer uma das duas condições expostas, quase todos preferiram relatar viagens antigas, o que os levou a contar os aspectos mais gerais dos acontecimentos vividos, não se restringindo a pequenos períodos e dando detalhes somente sobre uma ou duas experiências mais marcantes. O único que dividiu seu relato em partes com cabeçalhos foi R.G. Ainda assim, o estudante focou em um período específico de quase 20 dias, dando poucas informações sobre os outros trechos da viagem. Os alunos V.C. e G.S. aplicaram um cabeçalho com data e destino. G.S. optou por um relato fictício de uma viagem de dois dias somente. V.C. estruturou sua produção com organizadores temporais que faziam referência aos dias que havia passado viajando, até o terceiro dia, depois do qual foi usado um les jours suivantes genérico. A.S. fez o mesmo quanto aos organizadores, usando quand nous avons arrivés, en le jour suivant, en troisième jour e en le matin de suivant jour, apresentando dificuldade principalmente com preposições, mas facilidade em organizar temporalmente seu texto. Já C.S. relatou de maneira geral sua viagem, não especificando os dias em que cada evento havia ocorrido.

Assim, observamos que dificilmente seriam reproduzidos pelos alunos o nível de detalhamento e o formato de divisão típicos do gênero. A adequação, no entanto, do tema global do texto às expectativas do leitor era um ponto importante a ser desenvolvido ainda em relação às capacidades de ação. $\mathrm{O}$ aprendiz que apresentou maior dificuldade em adequar seu conteúdo aos propósitos do gênero foi R.F., que, em texto muito curto (apenas 64 palavras), não introduziu nenhuma informação que fosse válida para o destinatário. O aluno, escrevendo sobre uma ida ao litoral no réveillon, não especifica a qual cidade foi, nem relata quais suas impressões sobre o lugar. Por outro lado, a produção que melhor se encaixou aos propósitos do gênero foi a de R.G., que deu mais informações sobre a gastronomia e o modo de vida da região. Já os outros alunos relataram suas experiências de maneira satisfatória, usando diversas modalizações apreciativas, como: [plages] très belles,[rues] propres, plus organisé, une belle vue, la meilleure pizza, l'un des plus beaux paysages e les plus belles et agréables souvenirs. 
O uso de comparações foi constante e a aluna com mais facilidade para fazê-las foi V.C.

Por último, quanto à coesão verbal, todos os alunos preferiram fazer seus ralatos usando o passé composé e o imparfait, talvez por estarem mais familiarizados com o uso de tempos verbais pretéritos para abordar eventos passados; ou, ainda, pelo fato de que tinham acabado de estudá-lo nas aulas de Francês 2. Alguns problemas com a formação do passé composé, no entanto, são identificados na produção de R.F. ("Nous avons arrivé"). Já no texto de G.S., os três momentos em que o aluno opta pelo imparfait são inadequados, requerendo, na verdade, o uso do passé composé.Essse tipo de erro, entretanto, não tinha ocorrido na atividade anterior.

A quarta atividade propunha a produção de um email informal. Os alunos deveriam escrever a algum amigo fictício que tivesse obtido uma bolsa para estudar em algum país francófono, perguntando sobre o percurso necessário para obtenção do subsídio, assim como pedindo informações sobre o curso e sobre o alojamento na cidade de destino. Os alunos também deveriam perguntar o que o amigo vinha fazendo nos últimos meses, bem como relatar as atividades com que eles mesmos tinham se ocupado.

Como o gênero em questão está presente na língua materna dos estudantes e como faz parte do cotidiano de todos eles, as capacidades de ação não se apresentaram como problemáticas. A manutenção da informalidade foi operada por todos e nenhum mostrou dificuldade em se apropriar do papel social do enunciador, nem de cumprir as expectativas do leitor quanto ao conteúdo da mensagem. Portanto, o que se esperava dos estudantes é que fossem capazes de desenvolver um misto de relato e de discurso interativo, pertencente ao eixo do expor, usando a primeira e a segunda pessoa, empregando frases não declarativas, isto é, interrogativas, imperativas e exclamativas e fazendo uso de alguns dêiticos espaciais e temporais.

Começando por R.F., o aluno teve desempenho sensivelmente melhor nesta atividade, adequando-se ao gênero. Empregou dêiticos estabelecendo o cá e lá, ou seja, o Brasil e o país francófono do amigo e não mostrou problemas na escolha dos tempos verbais. Quanto à estrutura do passe composé, o aluno se confundiu unicamente quando se tratava de verbo pronominal na negativa ("tu n'ai m'écrit pas"). Já a aluna S.C. 
cometeu alguns erros quanto à conjugação de alguns verbos irregulares no presente ("tu vais faire", por exemplo).

Quanto ao restante dos alunos, todos obtiveram rendimento satisfatório no que diz respeito ao emprego de dêiticos e à coesão verbal. $\mathrm{O}$ imperativo foi usado corretamente pelos sete estudantes, com alguns erros na ortografia dos verbos irregulares. Vale também ressaltar que cinco deles incluíram verbos no futuro do pretérito em suas produções, demonstrando facilidade em modalizar suas falas. Expressões como "Je amarais savoir ces choses pour me preparer" (R.F.), "Tu pourrais m'informer" (A.S.) e "Je voudrais sauvoir" (S.C.) mostram que os alunos entreviram as reações de seu interlocutor e, portanto, amenizaram o que queriam dizer para parecerem polidos ou para não se mostrarem demasiadamente taxativos.

Chegando à última proposta de produção, os alunos deviam fazer um relato curto, usando como referência o livro de crônicas Enregistrements Pirates, de Phillipe Delerm (2004), que fora abordado em sala de aula durante todo o semestre.

A produção de R.F. apresenta sensível melhora nas capacidades de ação e nas discursivas. Se o aluno, na primeira produção, não conseguiu estabelecer a intriga e tampouco foi capaz de construir o suspense em sua sinopse, dessa vez apresenta relato totalmente pautado na angústia do desconhecido, instigando, assim, seu leitor. Em seu texto, uma personagem trabalha em casa, sozinha, quando ouve um barulho intrigante; ao final, descobrirá que fora somente seu gato. Durante todo o texto, o estudante adotou a perspectiva da personagem, a fim de passar ao leitor as mesmas sensações por ela experimentadas. No que tange às capacidades linguístico-discursivas, ainda persistem alguns erros quanto às preposições. No entanto, é preciso ressaltar a melhora no uso dos adjetivos possessivos, utilizados nessa produção sem cometer erros.

A produção da aluna A.S. também apresenta alguns pontos interessantes. A estudante decidiu abordar a importância cultural do sofá. Para tanto, usou muitas retomadas com inserção de índices de subjetividade ("Un espace démocratique idéal pour les discussions", por exemplo). Também é interessante observar o sistema de conexão criado sem inserção de organizadores padrão. Cada início de parágrafo determina o tema. Pode-se dizer, por exemplo, que enquanto o segundo parágrafo trata da comodidade do móvel, o terceiro evoca sua função de 
espaço social na casa.Também cabe notar que o texto começa e acaba com o mesmo tema: "Le temple d'une maison. / Un temple de la procrastination." Quanto à coesão verbal, a quantidade de verbos no infinitivo equipara-se à do presente, acompanhando a imobilidade do objeto e do texto, em que não há progressão de ações.

R.G. e C.S. apresentaram boas produções. R.G. revelou dificuldade com os pronoms personnels e toniques da terceira pessoa, mas conseguiu inserir elementos de interesse em seu texto, desenvolvendo-o a partir de imagens surreais que instigam o leitor, que espera entender a situação apresentada antes que o texto acabe. C.S. teve desempenho satisfatório, usando frequentemente os pronomes en e $y$, de difícil apropriação pelos alunos de francês. $\mathrm{O}$ aluno abordou o momento cotidiano do despertar, inserindo discurso indireto livre para adotar a perspectiva do protagonista. C.S., aliás, desenvolveu muito bem os três tipos de capacidades de linguagem, de modo que sua última produção é muito superior à primeira.

Já G.S. evocou a imagem de um cão e sua reação toda vez que via um caminhão de lixo passar, fazendo referência a um momento trivial, assim como a maioria dos alunos que também abordaram cenas da vida cotidiana. G.S., no entanto, apresentou certo retrocesso no uso do passé composé e imparfait. Na segunda produção escrita o aluno não apresentou problemas com nenhum dos dois tempos verbais. No terceiro, entretanto, houve confusão entre os momentos adequados ao uso de um e de outro. No exercício 4, em que usou somente o indicatif présent e o passé composé, não houve maiores problemas. $\mathrm{Na}$ última atividade, no entanto, em que foi necessário usar os dois tempos, o aluno os confundiu algumas vezes. O uso do présent foi satisfatório e permitiu ao estudante dar a impressão de continuidade indeterminada às reações do cão.

Tendo analisado o desempenho de cada aluno nas cinco produções escritas, notamos que a maioria iniciou o semestre com alguma dificuldade em adequar-se ao contexto do gênero que era pedido. Para a maior parte, o problema foi resolvido logo a partir da segunda produção escrita. R.F. e S.C., no entanto, como alunos com desempenho menor, demoraram mais algum tempo para adequar-se. A coesão verbal e a nominal mostraram ser um problema para boa parte dos alunos em alguns gêneros, mas a maioria mostrou ter feito progressos 
ao longo do semestre. Em relação às vozes, nenhum aluno apresentou problemas significativos. No que diz respeito às modalizações, observamos o uso inapropriado de modalizações apreciativas, revelando a opinião do produtor do texto na sinopse e a dificuldade de seu uso para caracterizar os personagens e referentes.

A seguir, anotamos a evolução de cada aluno em tabelas conforme as capacidades de linguagem que deveriam ser desenvolvidas. Vozes não foram inclusas, pois foram as que apresentaram menos dificuldades. As modalizações apreciativas foram incluídas na coesão nominal, pois diziam respeito às adjetivações e escolhas nominais. Decidimos adotar uma marcação objetiva, usando "•" para aspectos apropriados pelos aprendizes conforme o esperado e " $x$ " para aquilo que os estudantes não dominaram idealmente. Reconhecemos que existem níveis diferentes de apreensão de conteúdos e, nesse sentido, nossas tabelas que contemplam apenas duas opções não permitem dar conta da complexidade da aquisição das capacidades de linguagem. Sabemos também que uma tabela sumária jamais poderia expressar as nuances do aprendizado de uma língua estrangeira. Portanto, sendo demasiadamente objetivas para ilustrar o detalhamento do estudo, as tabelas pretendem dar somente um panorama geral da progressão dos alunos, a fim de entrever o percurso de cada um.

\begin{tabular}{|l|c|c|c|c|c|}
\hline & \multicolumn{5}{|c|}{ Capacidades de ação } \\
\hline Alunos & PE1 & PE2 & PE3 & PE4 & PE5 \\
\hline A.S. & $\mathrm{x}$ & $\mathrm{x}$ & $\bullet$ & $\bullet$ & $\bullet$ \\
\hline C.S. & $\mathrm{x}$ & & $\mathrm{x}$ & $\bullet$ & $\bullet$ \\
\hline G.S & $\mathrm{x}$ & $\mathrm{x}$ & $\bullet$ & $\bullet$ & $\bullet$ \\
\hline R.F. & $\mathrm{x}$ & $\mathrm{x}$ & $\mathrm{x}$ & $\bullet$ & $\bullet$ \\
\hline R.G. & $\mathrm{x}$ & $\bullet$ & $\bullet$ & $\bullet$ & $\bullet$ \\
\hline S.C. & $\bullet$ & $\mathrm{x}$ & & $\bullet$ & \\
\hline V.C. & $\mathrm{x}$ & $\bullet$ & $\bullet$ & $\bullet$ & \\
\hline
\end{tabular}

Tabela 3: Progressão das capacidades de ação dos alunos.

\begin{tabular}{|c|c|c|c|c|}
\hline \multicolumn{5}{|c|}{ Capacidades discursivas } \\
\hline PE1 & PE2 & PE3 & PE4 & PE5 \\
\hline $\mathrm{x}$ & $\mathrm{x}$ & $\bullet$ & $\bullet$ & $\bullet$ \\
\hline$\bullet$ & & $\mathrm{x}$ & $\bullet$ & $\bullet$ \\
\hline$\bullet$ & $\mathrm{x}$ & $\bullet$ & $\bullet$ & $\bullet$ \\
\hline $\mathrm{x}$ & $\mathrm{x}$ & $\mathrm{x}$ & $\bullet$ & $\bullet$ \\
\hline $\mathrm{x}$ & $\bullet$ & $\bullet$ & $\bullet$ & $\bullet$ \\
\hline$\bullet$ & $\mathrm{x}$ & & $\bullet$ & \\
\hline $\mathrm{x}$ & $\bullet$ & $\bullet$ & $\bullet$ & \\
\hline
\end{tabular}

Tabela 4: Progressão das capacidades discursivas dos alunos 


\begin{tabular}{|l|c|c|c|c|c|}
\hline \multicolumn{7}{|c|}{ Capacidades linguís } \\
\hline & \multicolumn{5}{|c|}{ Coesão verbal } \\
\hline Alunos & PE1 & PE2 & PE3 & PE4 & PE5 \\
\hline A.S. & $\bullet$ & $\bullet$ & $\bullet$ & $\bullet$ & $\bullet$ \\
\hline C.S. & $\bullet$ & & $\bullet$ & $\bullet$ & $\bullet$ \\
\hline G.S & $\bullet$ & $\bullet$ & $\mathrm{x}$ & $\bullet$ & $\mathrm{x}$ \\
\hline R.F. & $\mathrm{x}$ & $\bullet$ & $\mathrm{x}$ & $\mathrm{x}$ & $\bullet$ \\
\hline R.G. & $\bullet$ & $\bullet$ & $\bullet$ & $\bullet$ & $\bullet$ \\
\hline S.C. & $\bullet$ & $\mathrm{x}$ & & $\mathrm{x}$ & \\
\hline V.C. & $\bullet$ & $\bullet$ & $\bullet$ & $\bullet$ & \\
\hline
\end{tabular}

Tabela 5: Progressão das capacidades linguístico-discursivas (coesão verbal) dos alunos.

\section{Coesão nominal}

\begin{tabular}{|c|c|c|c|c|}
\hline \multicolumn{5}{|c|}{ Coesão nominal } \\
\hline PE1 & PE2 & PE3 & PE4 & PE5 \\
\hline$\bullet$ & $\bullet$ & $\bullet$ & $\bullet$ & $\bullet$ \\
\hline$\bullet$ & & $\bullet$ & $\bullet$ & $\bullet$ \\
\hline $\mathrm{x}$ & $\mathrm{x}$ & $\bullet$ & $\bullet$ & $\bullet$ \\
\hline$\bullet$ & $\mathrm{x}$ & $\mathrm{x}$ & $\bullet$ & $\bullet$ \\
\hline$\bullet$ & $\bullet$ & $\bullet$ & $\bullet$ & $\mathrm{x}$ \\
\hline$\bullet$ & $\mathrm{x}$ & & $\bullet$ & \\
\hline$\bullet$ & $\bullet$ & $\bullet$ & $\bullet$ & \\
\hline
\end{tabular}

Tabela 6: Progressão das capacidades linguístico-discursivas (coesão nominal).

\section{Considerações finais}

Neste artigo, tínhamos por objetivo apresentar os resultados de um estudo sobre a produção de textos escritos, baseados em cinco gêneros textuais por um grupo de estudantes universitários de Letras-francês. O intuito era o de verificar, durante um semestre, o desenvolvimento das capacidades de linguagem dos alunos, sobretudo as capacidades discursivas relacionadas à atividade de linguagem "relatar", por meio de atividades de produção textual realizadas em autonomia e diponibilizadas por meio da plataforma Moodle.

Com o estudo, pudemos comprovar a pertinência do trabalho com gêneros textuais para a aprendizagem da produção escrita em francês, já que os alunos mostraram o desenvolvimento de suas capacidades de linguagem, mesmo com o trabalho em semi-autonomia, por meio da plataforma Moodle. Mais do que isso, este estudo permitiu investigar a pertinência de se trabalhar, em um semestre, uma atividade linguageira isolada (em nosso caso, "relatar"), à maneira do que propõe Bronckart (2010), visando à concentração das dificuldades dos alunos em um aspecto apenas.

A análise das produções mostrou que, embora tivessem mais dificuldades, no início, com as capacidades de ação, aos poucos os alunos foram compreendendo a importância da mobilização do conhecimento sobre o contexto de produção, para a criação de uma situação de ação de linguagem adequa- 
da. Vimos, também, que o fato de ter que produzir um gênero mais próximo ao que já conhecem (como o email informal) é um fator importante para a mobilização das capacidades de ação, mas também das discursivas. Aliás, no que diz respeito especificamente às capacidades discursivas, observamos que é possível ter havido um desenvolvimento na sua mobilização ao longo das cinco atividades de produção escrita, pois vemos que a atividade de linguagem "relatar" parece ir se tornando mais satisfatoriamente apropriada pelos alunos. Por exemplo, a dificuldade na sinopse na criação da situação de interesse não ocorreu no relato de viagem. Finalmente, é importante observar que as capacidades linguístico-discursivas parecem ser as de apropriação mais difícil e são, também, mais dificilmente transferíveis da LM para LE, pois dependem do domínio específico das unidades de cada língua natural.

Esta pesquisa parece também ter evidenciado o papel dos gêneros enquanto instrumentos, pois, ao agirem nos processos psíquicos dos alunos, eles podem contribuir para o desenvolvimento de capacidades de linguagem. Nesse sentido, é essencial a continuidade de pesquisas que abordem o desenvolvimento das capacidades de linguagem dos alunos ao longo de vários textos, examinando as possíveis transferências de capacidades adquiridas em um gênero para outro. Também mostra-se relevante a realização de outras pesquisas que focalizem especificamente o desenvolvimento das capacidades linguístico-discursivas, principalmente em se tratando da aprendizagem de línguas estrangeiras, já que elas parecem ser de difícil aquisição e transferência da LM para a LE.

\section{REFERÊNCIAS}

BEZERRA, C. S. LOUSADA, E.G. Produção escrita em francês por meio de gêneros textuais: desafios da produção textual na universidade. Projeto Ensinar com Pesquisa, apresentado à Universidade de São Paulo em 2012.

BRONCKART, J.-P. Atividades de linguagem, textos e discursos. São Paulo: EDUC, 1999.

Atividades de linguagem, discurso e desenvolvimento humano. São Paulo: Mercado de Letras, 2006. 
BRONCKART, J.-P. O agir nos discursos: das concepções teóricas às concepções dos trabalhadores. São Paulo: Mercado de Letras, 2008.

Gêneros de textos, tipos de discurso e sequências. Por uma renovação do ensino da produção escrita. In: Letras, Santa Maria, v. 20, n. 40, p. 163-176, jan./jun. 2010.

BRONCKART, J.-P. et al. Le fonctionnement des discours. Un modèle psychologique et une méthode d'analyse. Paris: Delachaux \& Niestlé, 1985.

BUENO, L. Os gêneros jornalísticos e os livros didáticos. Campinas: Mercado de Letras, 2011.

COUTINHO, A. Dos géneros de textos à gramática. D.E.L.T.A., 28:1,p. 27-50. 2012.

CRISTOVÃO, V. L. O gênero quarta capa no ensino de inglês. In: DIONÍSIO, Â.; MACHADO, A. R.; BEZERRA, M. A. (Orgs.) Gêneros textuais e ensino. Rio de Janeiro: Lucerna, 2002.

. Estudos da linguagem à luz do Interacionismo Sociodiscursivo. Londrina: EDUEL, 2008.

Sequências didáticas para o ensino de línguas. In: DIAS, R. ; CRISTOVÃO, V. L.. (Org.). O Livro Didático de Lingua Estrangeira: múltiplas perspectivas. Campinas: Mercado de Letras, 2009.

DELERM, P. Enregistrements pirates. Mônaco: Éditions du Rocher, 2004.

DOLZ, J. ; GAGNON, R. ; TOULOU, S. Production écrite et difficultés d'apprentissage. Genève: FAPSE-Unige, 2008.

FAÏTA, D. Gêneros de discurso, gêneros de atividade, análise da atividade do professor. In: MACHADO, A. R. (Org.) O ensino como trabalho: uma abordagem discursiva. Londrina: Eduel, 2004. Le métier d'enseigner - O trabalho de ensinar. Conferência realizada pelo Ciclo de conferências O professor e seu trabalho, pela Área de Estudos Linguísticos, Literários e Tradutológicos em Francês da FFLCH-USP, 2011.

FRANCESCHINI, F. Notícia e reportagem: sutis diferenças. Comum, no. 22, 2004.

FRIEDRICH, J. Lev Vigotski: mediação, aprendizagem e desenvolvimento. Campinas: Mercado de Letras, 2012. 
GUIMARÃES, A. M. e KERSCH, D. F. Projetos didáticos de gênero na sala de aula de língua portuguesa. Campinas, Mercado de Letras, 2012.

; MACHADO, A. R. e COUTINHO, A. (Orgs.). O interacionismo sociodiscursivo: questões epistemológicas e metodológicas. Campinas, Mercado de Letras, 2007.

GUIMARÃES-SANTOS, L. O gênero itinéraire de voyage para pensar o agir social no ensino-aprendizagem do FLE. 2012. 260 p. Dissertação. Faculdade de Filosofia, Letras e Ciências Humanas - FFLCH, Universidade de São Paulo - USP. São Paulo: 2012.

LOUSADA, E.G. Produção Escrita em Francês como Segunda Língua: uma experiência baseada em gêneros textuais. Revista do GEL, Araraquara, v. 6, p. 160-174, 2009.

LOUSADA, E. G. Elaboração de material didático para o ensino de francês. In: DIONÍSIO, Â.; MACHADO, A. R.; BEZERRA, M. A. (orgs) Gêneros textuais e ensino. São Paulo: Parábola Editora, 2010.

LOUSADA, E. G. Gêneros textuais e perspectiva acional no ensino do francês como língua estrangeira: prescrições e instrumentos para o agir de alunos e professores. In: DIAS, Reinildes; DELL'ISOLA, Regina Lúcia Péret. Gêneros textuais: teoria e prática de ensino em LE. Campinas: Mercado de Letras, 2012, p. 99-123.

LOUSADA, E.G. MUNIZ-OLIVEIRA, S. BARRICELLI, E. Gêneros textuais em foco: instrumentos para o desenvolvimento de alunos e professores.Estudos Linguísticos, v. 40, p. 627-640, 2011. MACHADO, A. R. (org.) O ensino como trabalho. Uma abordagem discursiva. Londrina: Eduel, 2004.

MACHADO, A. R.; ABREU-TARDELLI, L. CRISTOVÃO, V. L. (Orgs). O ensino e a aprendizagem de gêneros textuais. Campinas: Mercado de Letras, 2009.

MACHADO, A.R.; LOUSADA, E.G. A apropriação de gêneros textuais pelo professor: em direção ao desenvolvimento pessoal e à evolução do "métier". Linguagem em (Dis)curso, Palhoça, SC, v. 10, n. 3, p. 619-633, set./dez. 2010.

MACHADO, A. R.; LOUSADA, E.G.; FERREIRA, A. (Orgs.). O professor e seu trabalho: a linguagem revelando práticas docentes. Campinas: Mercado de Letras, 2011. 
MACHADO, A. R.; LOUSADA, E.; ABREU-TARDELLI, L. Resumo. Coleção Leitura e Produção de textos técnicos e acadêmicos. São Paulo: Parábola Editorial, 2004a.

Resenha. Coleção Leitura e Produção de textos técnicos e acadêmicos. São Paulo: Parábola Editorial, 2004b.

- Planejar gêneros acadêmicos. Coleção Leitura e Produção de textos técnicos e acadêmicos. São Paulo: Parábola Editorial, 2005.

Trabalhos de Pesquisa. Coleção Leitura e Produção de textos técnicos e acadêmicos. São Paulo: Parábola Editorial, 2007. PETRECHE, C. A sequência didática nas aulas de língua inglesa do ensino médio e o desenvolvimento de capacidades de linguagem. In: CRISTOVÃO, Vera Lúcia. (Org.). Estudos da linguagem à luz do Interacionismo Sociodiscursivo. Londrina: Eduel, 2008.

ROCHA, S.; LOUSADA, E. G. Gêneros textuais e escrita criativa: intersecções possíveis no ensino-aprendizagem do francês como LE. Raído, vol 6. n. 11, p. 37-54.jan/jun 2012

RIESTRA, D. Para debatir. ¿Cómo surgen y cómo llegan las propuestas didácticas? El Toldo de Astier, vol. 1, no. 1.2010.

SCHNEUWLY, B.; DOLZ, J. Gêneros orais e escritos na escola. Campinas: Mercado de Letras, 2004.

VIGOTSKI, L. Pensée et Langage[1934]. Paris: La dispute, 1997.

VIGOTSKI, L. Teoria e método em psicologia [1982]. São Paulo: Martins Fontes, 2004.

VOLOCHINOV, V. Marxisme et philosophie du langage[1929]. Paris : Les éditions de minuit, 1977. 


\section{Abstract \\ Written production and development of the language learning activity "reporting": an experience with undergraduate students using the Moodle platform}

This article aims at presenting a study of written production of undergraduate students that learn French as a Second Language, taking into account the role of text production as an instrument of language capacities development. In order to do so, the research is based on the theoretical framework of the SocioDiscursive Interactionism (SDI), according to the studies of Bronckart (1999, 2006, 2008), especially concerning about the use of text genres as a means for teaching and learning languages (Schneuwly; Dolz, 2004). The study consisted in the analysis of the written productions of undergraduate students taking the second semester of French as a Second Language, through the textual analyses model of the SDI, which includes the context of production and text architecture. The texts produced by the students were analysed in order to understand their learning path and identify how the students get in contact with the different social roles that they assume in each situation, besides verifying how these conditions reflect on the acquisition of language capacities (action, discursive and linguistic-discursive). The results show the appropriateness of this approach to the development of language capacities and, therefore, to the learning of written production in French.

Key words: Written production. Language activity. Text genre. 